\section{Georg Brandes' store Italiensrejse}

at ark il ar, cund.phil. I xemn Jaurnemen'

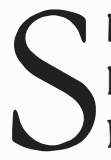

hacegget s ar nytrimmet egr haret lagt 1 moderigtige folder, da (ieorrg Brander den 2. nosember 1 $1 r^{-1}$ tradte ind i et propfỵldt auditorium pa Kollenhar no I'niscrsitet (1) indledte sine shelsecttende forclexninger orer "Hosedstrumninger 1 det 1")de arhundredes litteratur". Nu harde der laenge nosk videt

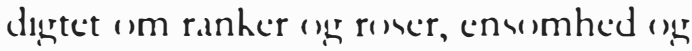
remod 1 det nords estlige hiorne af Feu repa. Tiden sar inde til, at litteraturen blev girurt moderne red at sette problemer til delat, eg fra uniserestetete talerstes meldte Brandes sig nu som bannerforer i den grede halges teneste.

Humoret fejlede hestemt ihe noeret, den digr "det moderne gennem hrud" sling ned 1 dansh litteratur. Brandes var glad, shher 1 sn fremtening og n.er mest struttede af sels tillid. () g hoorfor shulle han the enga det? Kirt for han indledte sne herome forelesninger pa unis cerstetet, sar han nemlie hiemsendt fra en 16 maneder lang danneleserejec, der hlandt andet hed pa et sanucligt or helt uforglemmeligt mode med Italien. Det lyar ud af hoer en satnines a de hrese, han shres par rejeen.

Bresene upherares I day i Brandes Irheret pa Det Kinneclige

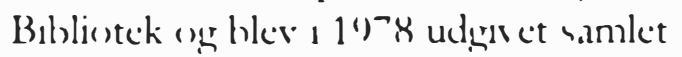
i trehindss derhet Cererg Bramders. Brete th

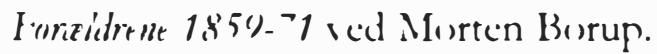

\section{Skidt fra start}

$\mathrm{M}$ ed rejefefeber i hele kroppen og forventningen spandt til bristepunktet forloxd den 28 -arige (jeorg Brandes Kobenharn den 5. april 18 (1) for at drage ud pa sin store Italiensrejes. Ad en rute, der blandt andet besd pa ophold i Hamborg, Paris og London, ankom Brandes den 11. september til den lille norditalienske landuby Susa. Hér tog Brandes sine forste skridt pa italiensk grund og kunne de folgende uger sende foraldrene i Kishenharn sansemattede hesogrsapporter fra byerne Torino, Milano og Firenze.

Da Brandes i slutningen af (wtoher ankom til Rom, gik det imidlertid galt. Den frydefulde rejefecher forvandkede sig til en uhehagelig, sygdomshetinget feher, og Brandes matte lide den tort at lade sig indlaggre pa et houpital red (apitolium til behandling for ty fur.

() in in ulyke kommer sjeldent alene. Nixpe var Brander bleret udehre vet fra houpitalet, helbredt for un ty fus, for nie helhredemasulge genorordigheder meldte sig. I et brev til fordeldrenc, dateret 22. januar 1 $\mathrm{R}^{-1} 1$, epsummerede Brandes situaturenen saledes:

"Da jecr lada para Hompitalet sarde Dencturen en Daier tel mie: Da.ar rel Feheren er orerstadet, pleser efter Tiphus alud at follece en eller anden I fferrec; I n faxer Honte, I n faler ( )ndt a Halnen, I.n 1

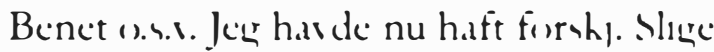
( )nder: Heste, hele Mund ene (i.ane fuld af Bleener o.m. oe taenhte at rere fierdis. Nuer ul alt I held den store Heredalare 1 mit houre Ben stoppet sad hele lienet er "sulmet we debleclt sata toht wim det andet

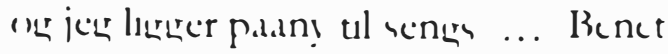
or en Bly manee orer hollhen ger har tabt al Mart ing end ea han flitte en Smule 1 


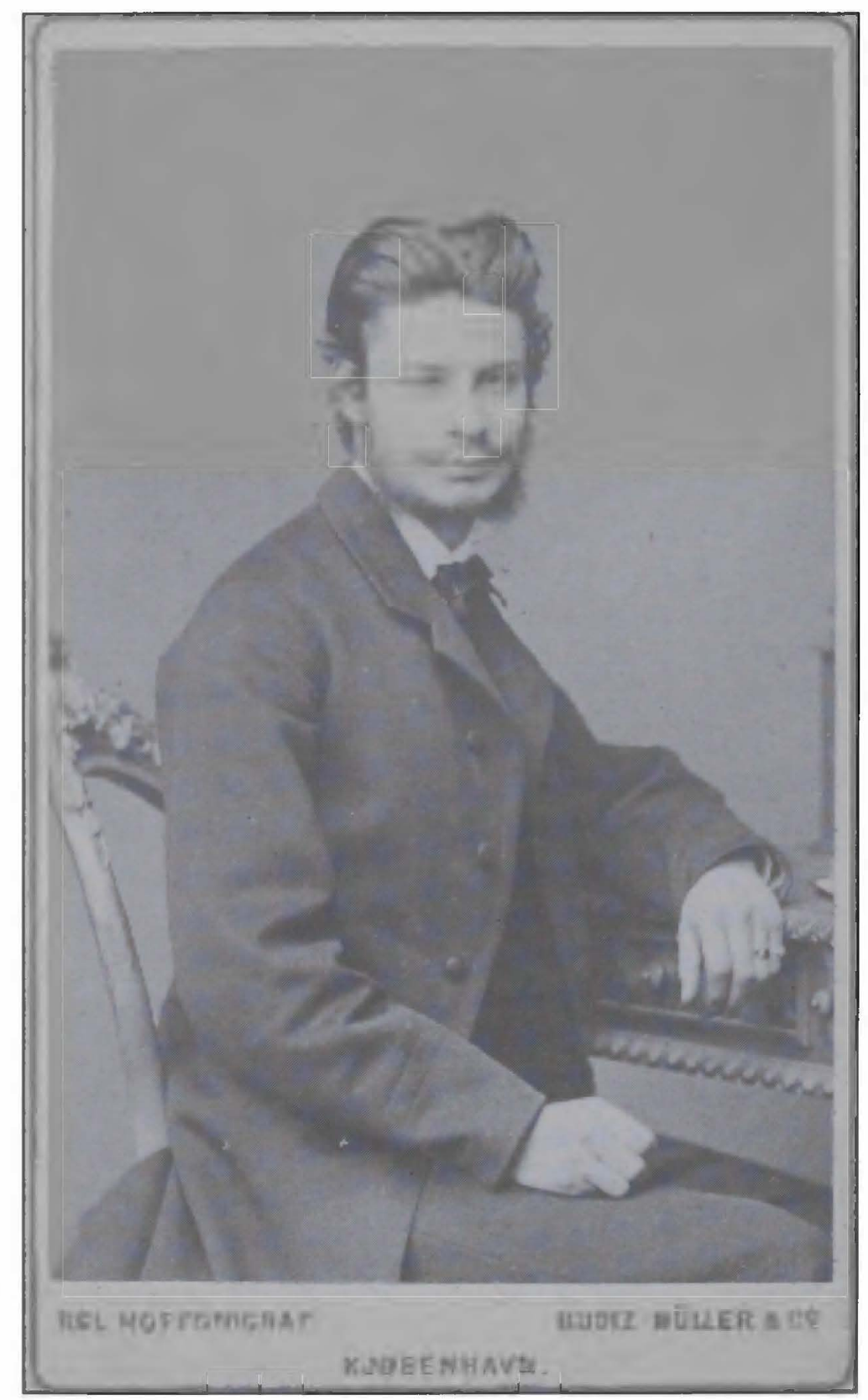

Georg Brande's (1872-19?7).

Ge'org Brandes l'ar en it'rin rejse'nde; ture'n yik. ik.ke' k.un til Italien, men til de fleste euruparisker lande' ong bon'edstader. Hans internationale

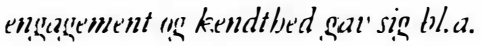
udslagy $i$ aresmedlemsskabur af en lang rak:ke. udenlandske. litterare foreninger, beriblandt The American - Aiademy of . Arts and Sicinces, de'n russiske forfatte'fre'ning samt The Roval Sinciety' of Literature $i$ London (Det Kongelige Bibliotek.).

Sengen. Tilmed mange Smerter."1

Brandes fik konstateret en alvorlig arebetændelse i benet og var de folgende maneder atter bundet til sengen. Han indlogerede sig i et lille værelse hos en italiensk händværkerfamilie, bestaende af snedkeren Lupi, hans kone Anna Maria og deres 19-årige niece Philomele. $\checkmark$ 'rtsfamilen tog sig kærligt af den danske patient og plejede ham efter alle kunstens

regler. ()g selv om Brandes med sin sygdomshistorie unægtelig var $\mathrm{k}(\mathrm{m} m \mathrm{~m} e t \mathrm{skidt}$ fra start pa sin store Italiensrejse, sa forsogte han ihærdigt at holde humoret hojt. I læselampens skær og med bogstabler inden for rækkevidde begav han sig fra sit smertefulde sygeleje via bogerne ud pà en befriende rejse i sit kammer. Han læste med stor interesse om italiensk politik, kunst og kultur, kun afbrudt af tre daglige maltider, morgenkaffe 


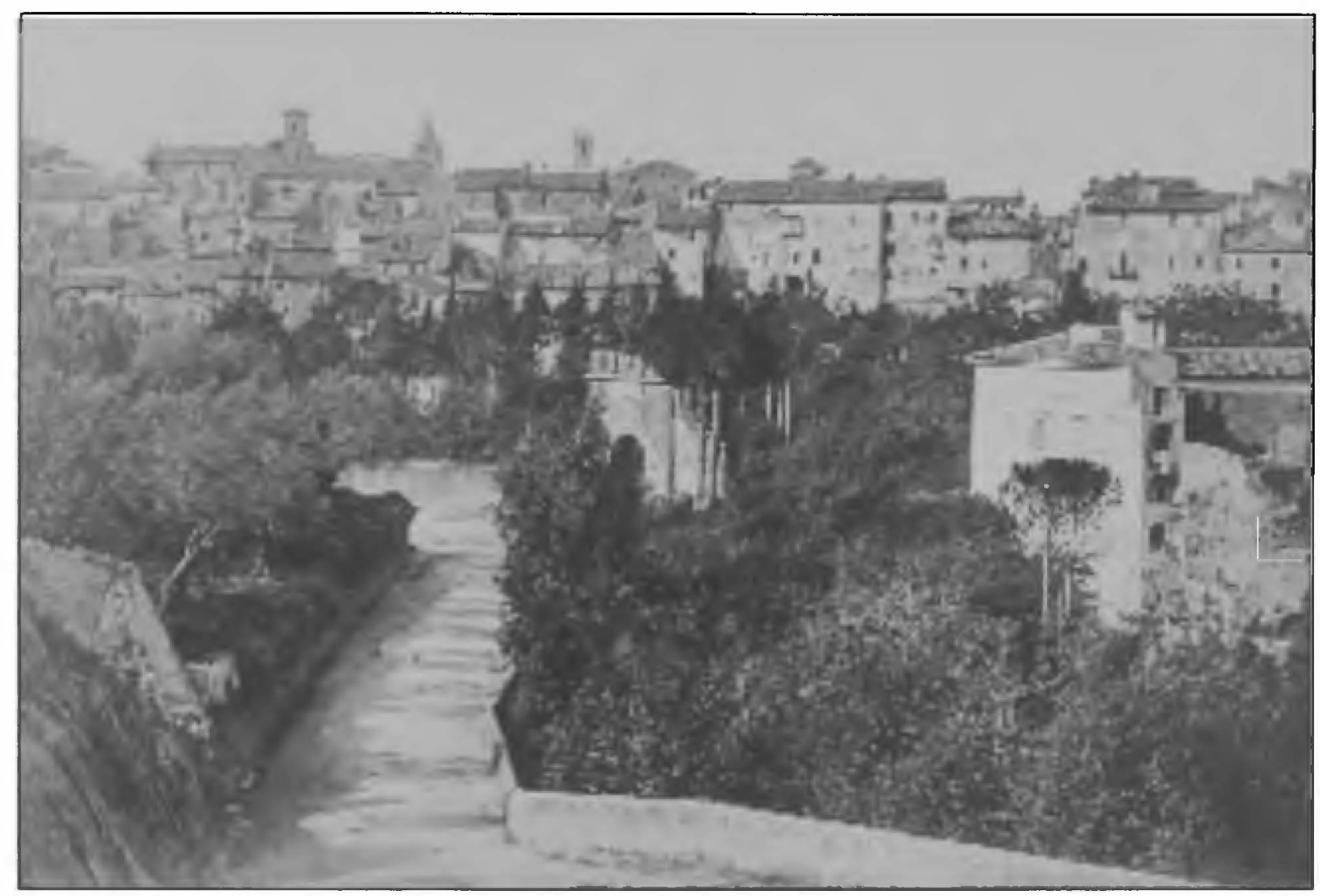

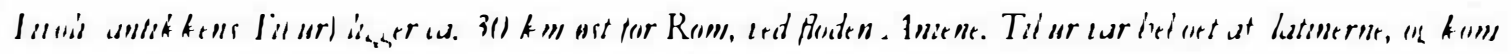

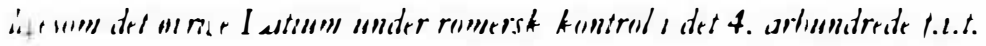

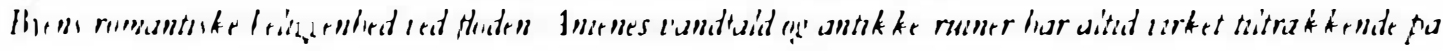

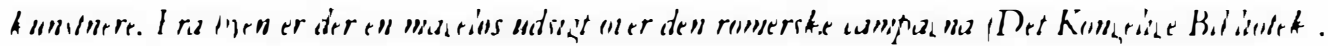

(1) dfenthe - og 1 ny oge noe et sodt besoge af den unge Philomele. For nok var Brancles plaget af mange smerter oget hojice ben 1 dobhele storrelse, men han var fra st puderar stadig 1 stand til at mande ug op til et alsorligt charmefremeted: "Jegr forfreshede min sige Persen red at betragte saa megen I'ngdom, Sundhed, Sty rhe og ( jlade 1 al Magr, sa sagde jeg hende nogle renlige ( )rd, ("ge opmuntret heraf hrod hun ud a en Strom af Veltalenhed uden Mage om al den (jlade hun lorede sig", som Brandes hetrocele un morr et bres shreset 14. februar $1 \mathrm{X}^{\top} 1 .^{2}$

Brander onte selulligt af une kunduhaber, og Philomele rels illigrt af sin shonhed; de diskuterede les ets sterre sporgermal, Hirtede flattigt og udsechslede hede farntag i den romershe nat. Det hialp gevaldigt pa patientens humor, og da arebetandelesen (gy smerterne 1 benet tilmed sar hraftigt pa retur, war Brandes $i$ lobet af kort tid endelig klar ul reje fra sy fra sigelejet og hegive sig ud pa det lange rentede italienshe exenty $r$.

\section{Halvgal af lykke}

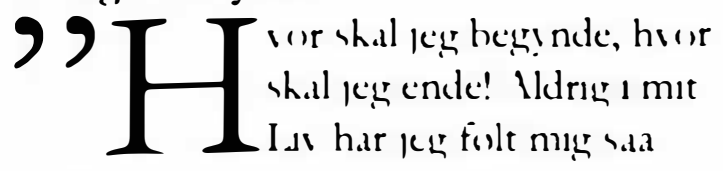

lyhhelig som nu. ... kegr forrelsher mig

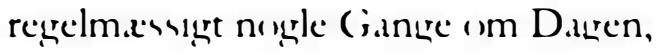

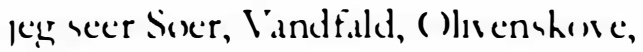
Daturomgerselece oserhesedet, mod hoslhe Trollhatta er Moge, leg har et Permes tal det usunate Kapel, Laggerer og Stanaer 


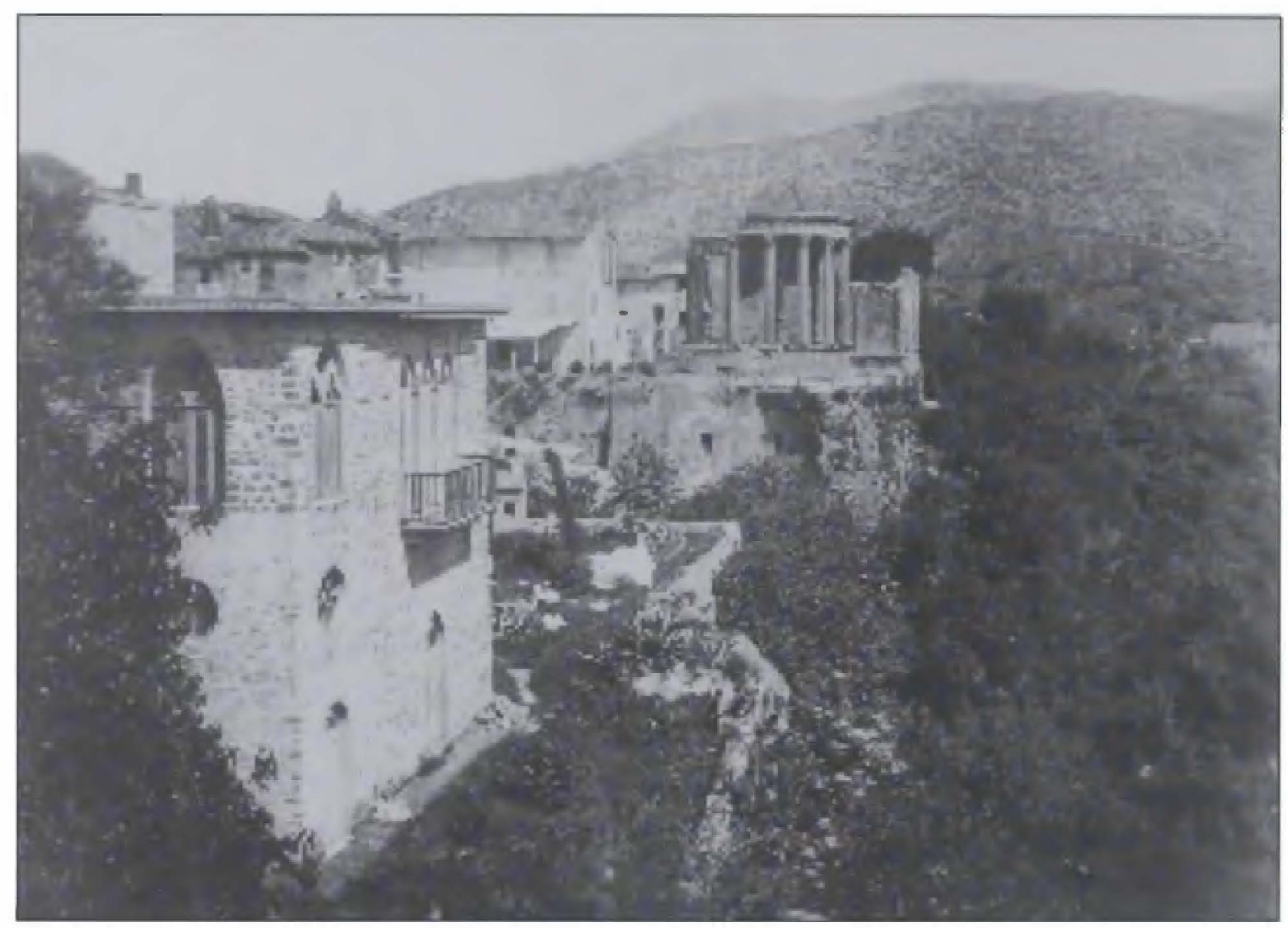

Tì'oli - til bojre Tempio della Silyrlla. Det rektangulare Sibylla-tempel er fra 2. arh. f.t.t., i jonisk stil. Fra tempelomradet (det antikeke romerske akropolis) er der smuk udsigt til I 'illa Gregoriana og v'andfaldet lige under Ponte Gregniano. (Det Kongelige Bibliotek).

i min Lomme, jeg er bogstaveligt halvgal af Lykke. Hvis jeg var mindre drukken af Henrykkelse skulde jeg forsoge at beskrive. Jeg vil kun sige: Af alt hvad jeg har seet paa Jorden er Tivoli det Skjonneste." ${ }^{3}$

Så begejstret lod det fra den restituerede Brandes i et brev til forældrene, dateret 17. april 1871. Han havde netop været på en af sine forste længere vandringer rundt i Roms omegn, blandt andet til byen Tivoli, og dér oplevet så meget skonhed, natur og poesi, at selv det halve ville have været fuld valuta for pengene. Med omme fodder og overophedet sanseapparat greb Brandes pen og brevpapir i et forsog på at fastholde et lille stykke af det Italien, han havde modt i Tivoli:

"Jeg glemmer aldrig Indgan- gen til en Gade i Tiroli: af en gammel Bue-Mur var kun Buen selv tilbage, paa den ene Side var Alt faldet ned lige til dens Linie, paa den anden gik Muren hoit i Veiret. Men hror der manglede Mur voxede en Kjæmpekaktus op fra Buen og spændte sine Blade til alle sider. Det var et fuldstændigt Maleri. Man kunde intet mere malerisk Udtænkt finde. Kort sagt her er Livet, Skjonheden og Virkeligheden. Her er Solen, Varmen og Lyset. Her er Farven, Formen og Linien, som Bjergene danne mod Horizonten, denne kunstneriske Baggrund for alle de andre Farver og Former."4

Brandes var overlykkelig og i sit es. Med ojne på stilke og eventyret sitrende i hver en nervetråd lod han alle 


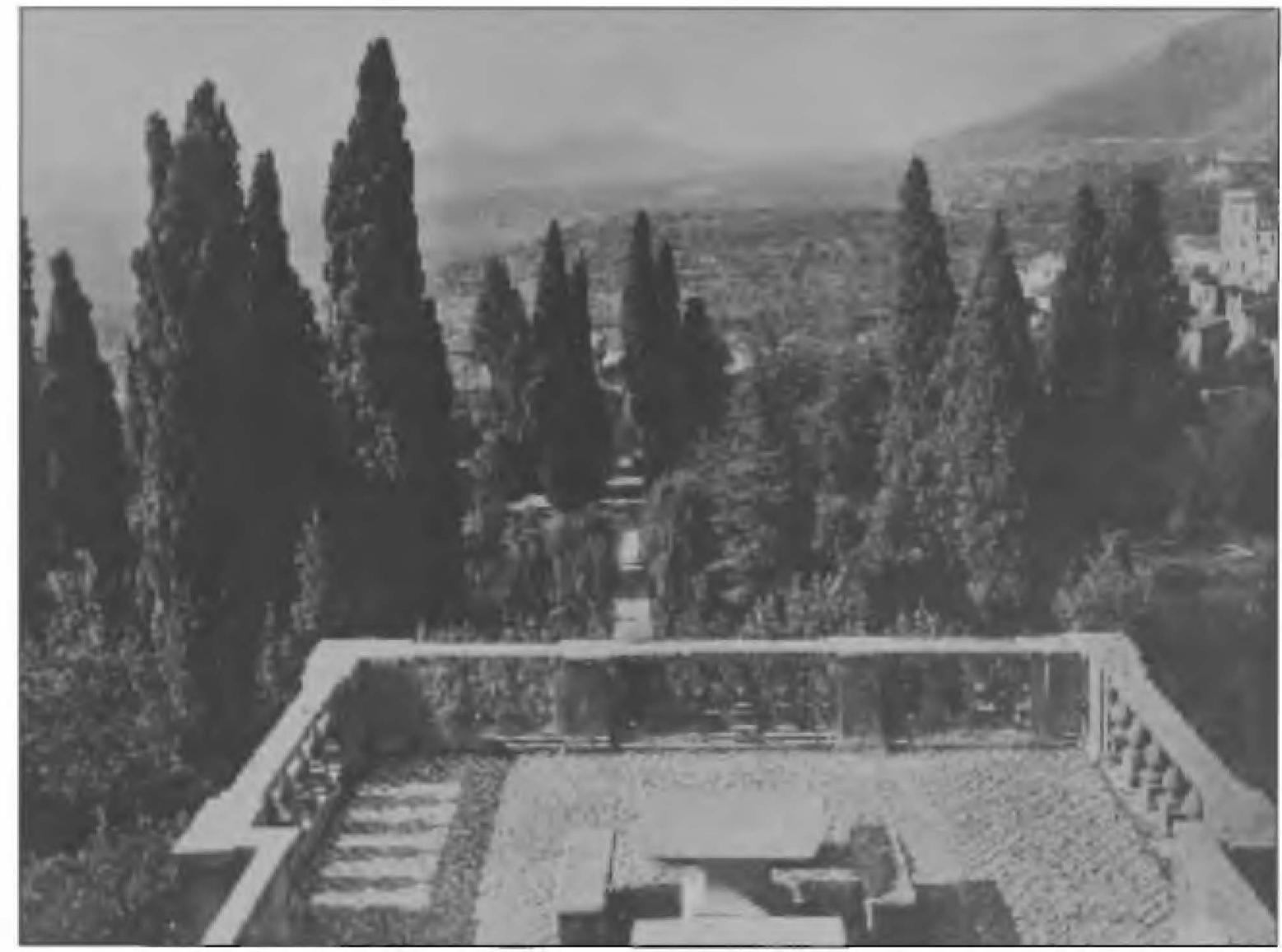

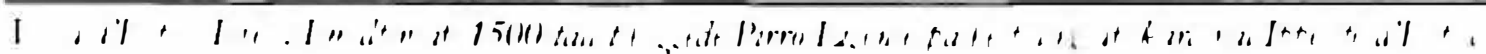

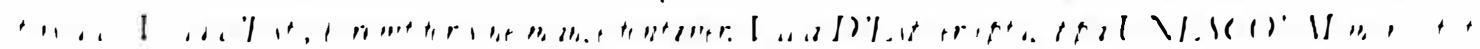
$\|, 1, H / h\|,$,$i .$

parader filde ag abnede une for de manere opleselecr, der 1 en lend atrom hod aig til. som fir chempel den udalet der modec

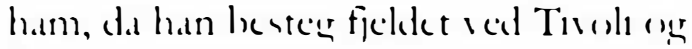
fra hopderne hask fuldt uden tel en reche

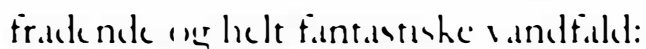

"I et sted filder det ned a klip pehulen, herencke sert, det er urom Jedetier neneren tal Tartarrus, et andet sted leer det amelende a he hlunhende med Vellenener af

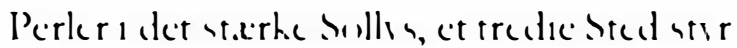
terden stere ( ascade ned wer hlipperne. Van haser lanem ad I gldreegen the uken Vansheliehedoef are til man staker arerfior den. Yan secr paden ae secer lntet uden det rasende shumberk l.and, det

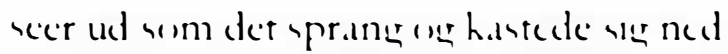
ad hlippen, som de storende ane sidende

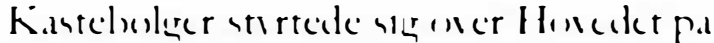

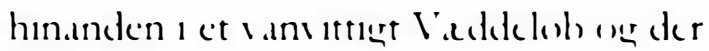
er en adad.an V.ant deri at man drases, liece urm grlider ned med a lf erunden are a han

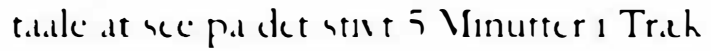
uden at fisk urmen Vasn, derminerer en med."

Brandes hasde ramsle contelt

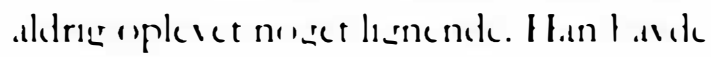

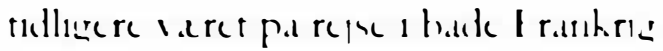
ae I neland, men met eted nial meal

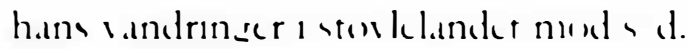
b.andfildene hruacke aceralt, t I_lene

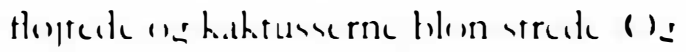

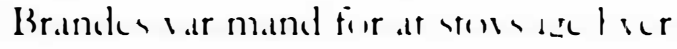
en hiddratmeter af det willdagte land, a

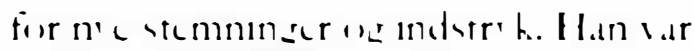

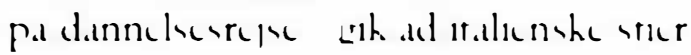




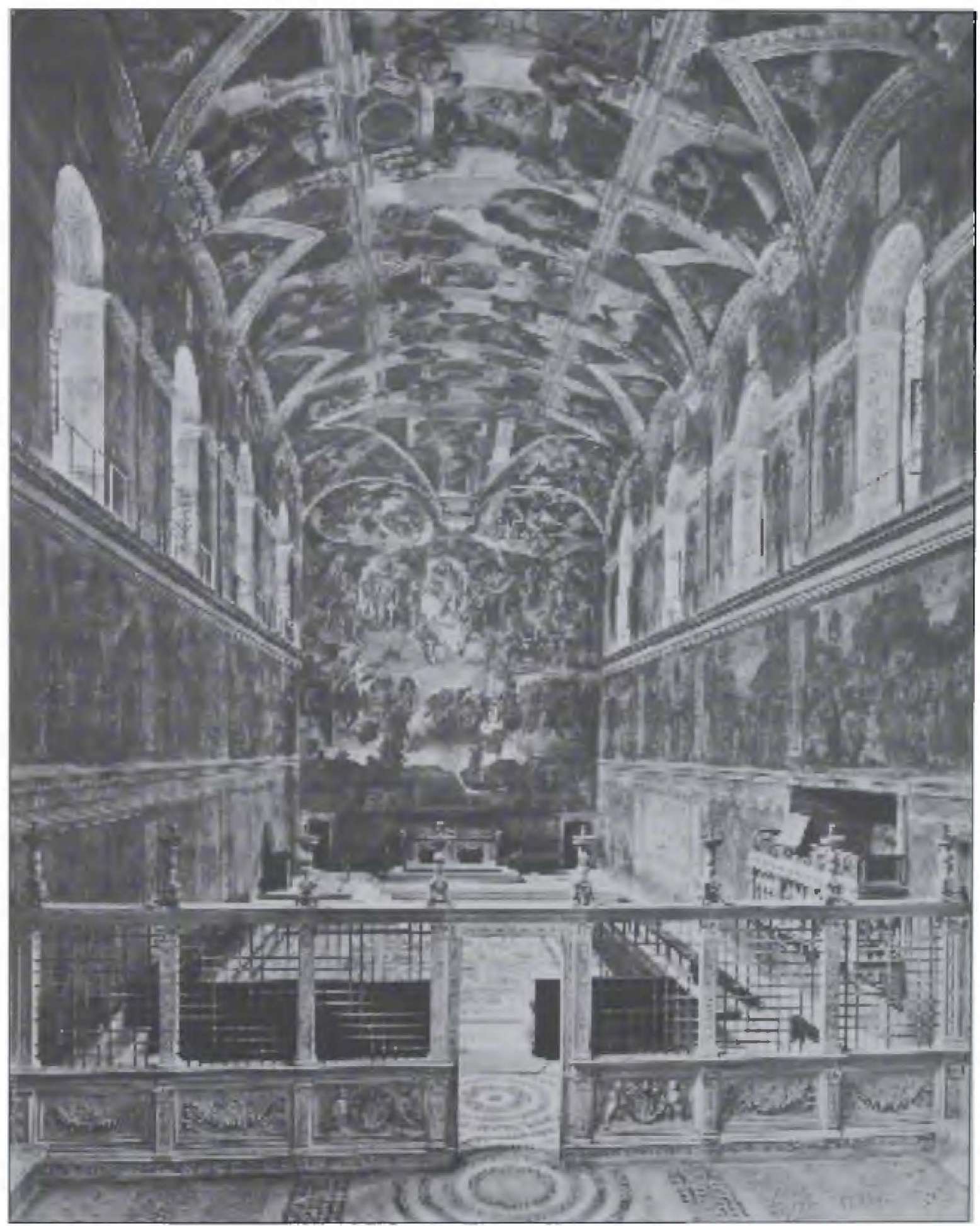

Det sixtinske. kappel er par'ens private kappel. Loftet blet' malet af .Michelangelo (Bunnarntti) mellem 15018 og 1512 pa bestilling fra par'e Julius II. Malerierne viser scener fra Skabelsen pa ca. $520 \mathrm{~m}^{2}$ og indeholder 115 skikekelser (Det Kongelige Bibliotek). 
par rej tal sit exeet jeer. Han samlede tanher, refleh somer ogerfaringer on hlistrede dem som uma hushesedler op pa sindets inder

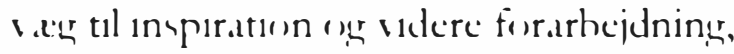
nar han efter endt rejue atter satte sier tal shriscluridet 1 I).anmarh.

\section{En verden i et billede}

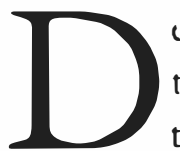
et sar ihhe hun landehabet ag na turen, der lob) som en s arm lasas trum gennem Brander' nerresis

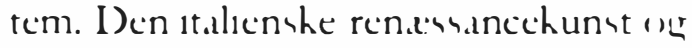
herlye Michelanecles malereer eg shulpturer Liorde et uforelemmeligt inder!h pa ham. Brandes hendte Mechelangelos som sin ceren buhaclomme. Han harde studeret

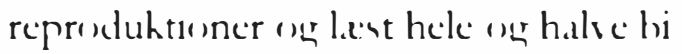
blesteher om den heromte hunenere lis as r.erh, men under opholdet i Rom 1 fordaret

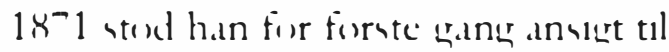
ansigt med den acerte vare.

()ir har man halet Rom ise

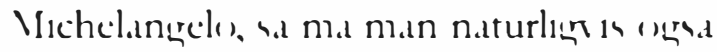

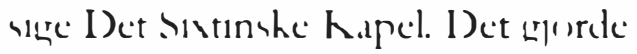

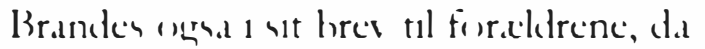
teret den 4. aprel 1h 1 1, hour han beshriver att moxte med Vachelangelos beromte liftmalere saledes: "les stader her endelie, indeluhhet med en land, der horer tel de 4 eller 5 atorste, der har leret. leerer uckenfor forcten age Venneshene. Her er hane Jurd "er hane Vennesher. Han har befollhet en verden 1 it billecke."

smat tre tmer bles det til a Det Sistinate hapel, hor Brander med

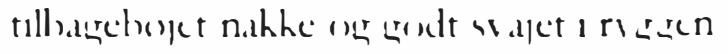

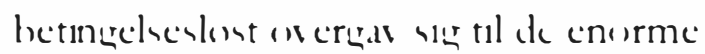
fresher, der foldede sir ud holt eppe orer ham. I arserne danecde, fieurerne fih lis, as aldrier harde Brandes opleset et maler1 4 . starht ogentenet urm nu:

"If Micterbillederne s.ar der incer to, der 1 ( )rigrnalen slone mer som orer al Kritih. (jud, der shaher solen, flyonde 1 umadadelin Fart giennem Rummet seet forst fr.d Insygtet sad fr.d Ryguren. Der er et udadant Punt i dette Billecle som $\mathrm{i}$ intet Indet. I)ernast Sindefaldet, hor I xas shjunhed tilienutre 1 Billedet er som en lalenbaring af hrorleden Men nesheheden egrentlig shulde have ixret. dedame Shabele kjendte jeer noicre forud. I'deryhtet 1 han Ansigt a ar mindre umagtende end jegr harde trocet, han umiler

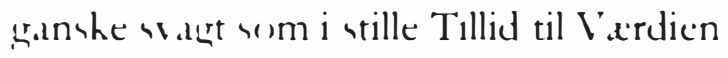
af det Liv, der nu fra (iude I inerer shal hlace orer i ham. Det lider nasten som en Loign, at een Mand har girurt dette 122 Maraneder."

I en sansecheplesuen af former og farrer her agede Branden sler rundt under det magertiege loffermaleri. Detalker

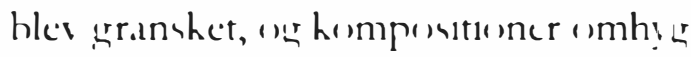
erelient analyacret, ar pludacles hunne den

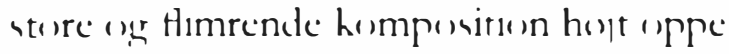
under taget pludacler amle us 1 hlare

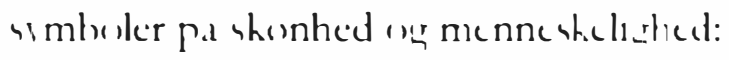
"... det rar Vichel Inzeliu

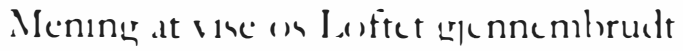

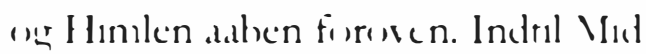
terbillederne mada det tanhes wom am

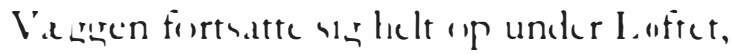

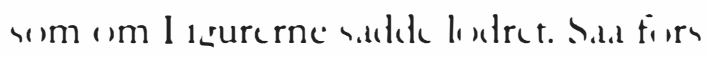

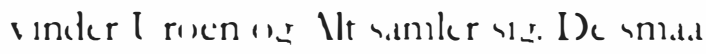

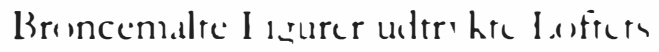
spandingerer Holle, de cre areliatehtom she s molukr. I lithen af une Herex omhrine Vedterbillederne cre V. I.

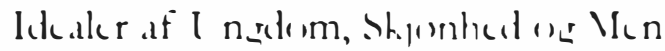

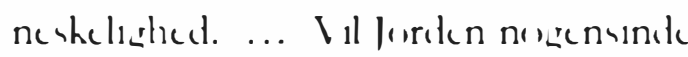

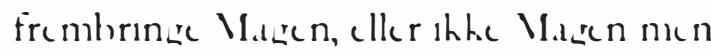
Vinect af uamme R.ınL?"”

Brandes' he undrme af Vict el

aneclis harde lanere raret utror, men 1

Det sistanshe K.apel nar den uanude

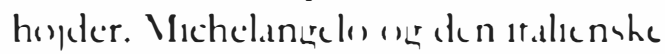


renæssancekunst var for Brandes en karkommen rekonstruktion af en tid, horor sanserne og folelserne harde frit lob ()g gav næring til det enkelte menneskes umattelige lirsappetit ng lyst til at udforske kunsten, kulturen og videnskaben.

Det var saledes en beriget og yderst oploftet Brandes, der rundede sit romerske kapelbesrog af med folgende ord: "I Naturen findes ikke Sligt, i Livet har jeg aldrig seet saadan Alvor, saadan Storhed ogy Eensomhed. Michel Angelo har folt storre, eensommere og mægtigere end noget andet Menneske. Han har ei givet Udtryk til Tanker vi andre maaskee nok kunde have haft, men manglet Udtrykket for. Han har skabt et Indre, hvis Beskaffenhed var mere end menneskeligt."

\section{Italien for altid}

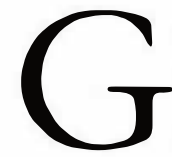
eorg Brandes' dannelsesrejse til Italien i 187()-1871 rumsterede lange $i$ bevidstheden og satte dybe spor i hans forfatterskab. Hans oplerelse af italiensk natur og renæssancekunst skærpede hans sanser (og gar ham en tro pa kunsten som en integreret del af livet. Derfor ville Brandes modernisere litteraturen. Den skulle vare debatskabende, handle om mennesker af kod og blod og skildre deres tanker, folelser og sansede virkelighed. Det var det, han giorde klart, da han ved sin hjemkomst fra Italien med ny kraft og inspiration tradte op med sine "Hovedstromningsforelæsninger" og erklærede romantikken i dansk litteratur for stendod.

Brandes' Italiensrejse bler ikke bare afyorrende for hans opgror med romantikken; den udloste en livslang forelskelse i landet: "Hrilken Lykke maa det ikke være at være Italiener, at sige til sig selv, dette er Blod af mit Blod, alt dette har mit Folk og mit Fædreland frembragt!", som han begejstret skrev hjem til forældrene i juli 1871. "' ()g kærligheden til landet var intakt, da Brandes godt 35 ar senere satte sig til skrivebordet for at nedfælde sine erindringer i trebindsvarket Leined. Hér indkredsede han med folgende lovord betydningen af sit skelsættende mode med Italien:

"Neppe en Dag var uden Udbytte af blivende Art, og neppe en er gaaet mig af Minde. Jeg levede forst og

\section{Syindefaldet, detalje af Michelangelos udsmy kning of loftet i Det. Sixtinsker Kapel.}

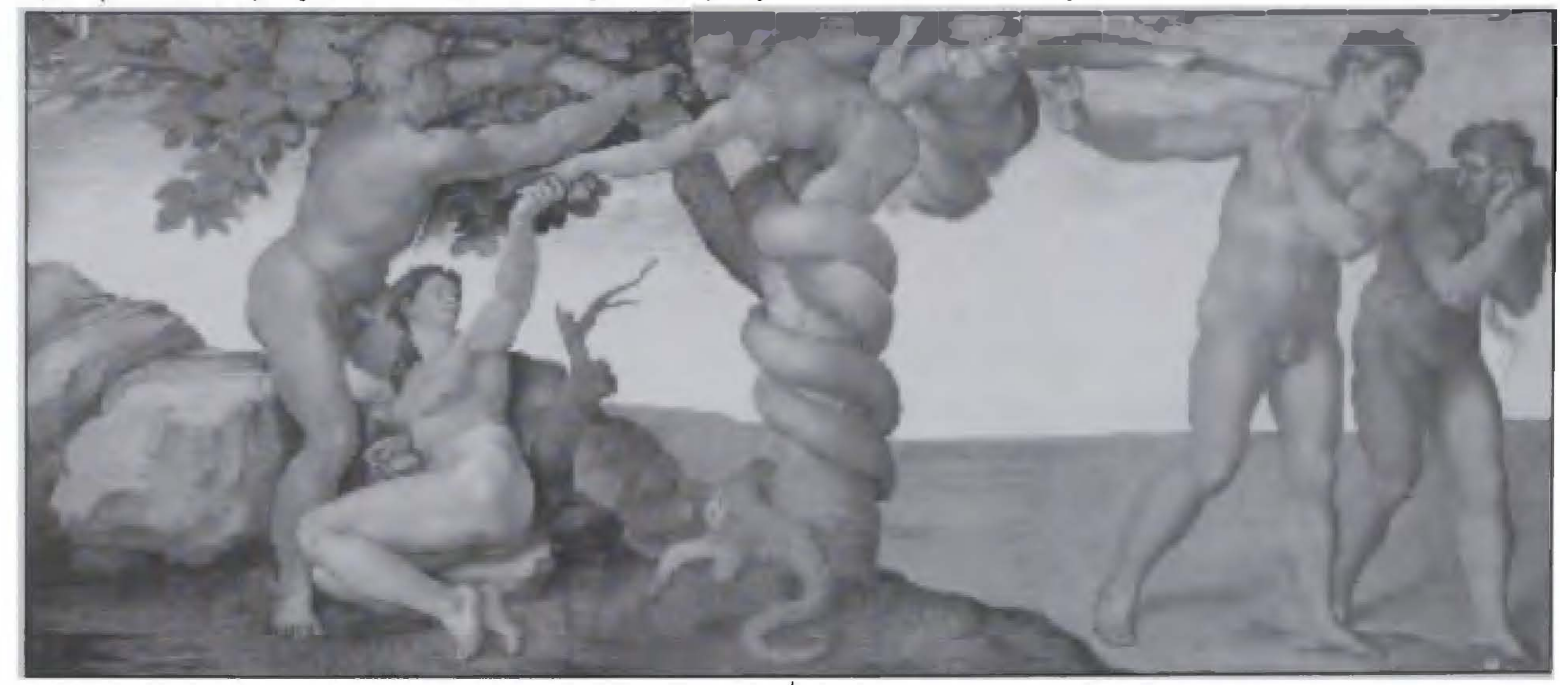


fremment gennem sinet, s wexlgede i ( )jenlist red shuet af Naturen, af Nennenher, if en Kunst, srom starede til denne Natur cer det Mennesheliv; der i Iortiden var levet 1 den. Jegr forregede daglig min Kundskabs sum, larrte nydende on nod det at lare.

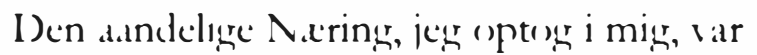
den, hwreffer jegr hasde imxigtet, og at det s.ar den, hourtil jegr trangte, heriste den Idenshal), hormed jegr tilegnede migr den. Min sinshredu udideder, idet jegr folte meg loffet tel adandelige I lojder, horerpad jegr ihhe hadtil harde stalet. Min I ir nglade hlusede "ep, idet jegr uaflerudt fornam. Hollhen Rierderm af Shonhed den italienshe Renasuance has de udbredt orer de relignede I gne, horre den hasde rokeset ule utor cur ut.erh." I

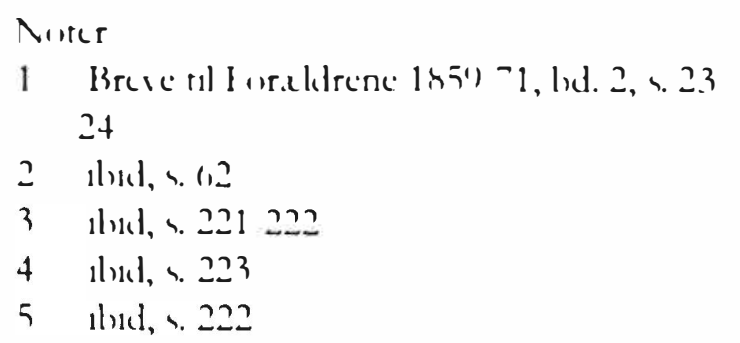

Videhegraxligheden sar uhegraxnet og iagttageluesernen i top, nar Italien stykike forr stykke tonnede frem. Der sar ikke tale om organiseret on hxublxuende sightsecing med snapshots af alle de traditionelle sevierdigheder $i$ Branden' rejuchreve. Men derimod Italien (eplevet i slowmotion (1g slentretempos med tid til hade slingrevals, af stikkere i ukendte gyder og eftertaxk w m trippen pa stedet.

Italien varsom en verden af muligheder, der abnede uig forr ham, hror landskabet, kuniten, vinen og kisinderne herusede ham. Stevilelandet mod 4 d a ar forr alvere gact Brandes i hlodet. Nu var han klar til at erobre unirersitetete taler stol og indlede sit felttog for at reformere andalivet i Danmark.

(1) Ilind, 4. 11)

- lind, s. 11)

$x$ ilid, s. 115

1) ihid, s. 1'\%

11) ibid, s. 3')

11 I.erned, hd. 2, ५. 1 